\title{
البحث عن الإسلام قراءة في "السلطة في الإسلام"
}

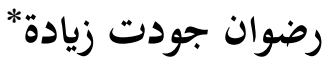

إذا كان الجابري قد انتهى في دراسته لـ (نقد العقل العربي): (بأن العربي عقلٌ يتعامل مع الألفاظ أكثر مما يتعامل مع المفاهيم، ولا يفكر إلا انطلاقاً من أصلٍ أو انتهاءً إليه أو بتوجيه منه، الأصل الذي يحمل معه سلطة السلف إما في لفظه وإما في معناه، وإن آليته، آلية هذا العقل في تحصيل المعرفة -ولا نقول في إنتاجها- هي المقاربة والمماثلة معتمداً على التجويز كمبدأ، كقانون يؤسس منهجه في التفكير ورؤيته للعالم).

فإن كاتب السلطة في الإسلام يرى أن العقل الإسلامي "الراهن" يتجاهل بدرجة مؤسفة اعتبارات

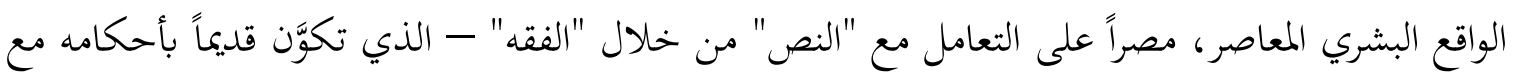
النص- فهم الشريعة من خلال السلف، والنتيجة لن تكون لإلا تغييباً للواقع الراهن خلف واقع السلف، هنا يفتقد النص طاقته التشغيلية الكاملة، ويظهر ذلك بوضوح في الفجوة الفاصلة بينه وبين العصر، وليس ذلك مقتصراً على العقل الإسلامي "المعاصر" أو "الراهن"، بل يؤكد على أن التعامل مع النص من خلال "سلفٍ ما" هو عادةٌ سلفية مستقرة، وحسب تعبيره فإن السلف أنفسهم كانوا "سلفيين" منذ البواكير الأولى.

لكنه يعود ليقرر أن لذلك ما يبرره لا سيما في هيمنة المنهج اللغوي إحساساً من هذا العقل في لا شعوره بمحدودية النص أو ثباته، فلقد كان من الطبيعي في ظل هيمنة هذا المنهج، أن يعجز العقل الفقهي عن التوصل إلى "قانون للنص" أي مبادئ الحركة التي تحكم عمل النص في الزمان، تلك المبادئ التي تكشف في النص عن قدرة ذاتية على التمدد في الزمن من غير حاجة إلى مساعدة خارجية، ذلك أن النص في الحقيقة ليس محدوداً ولا ثابتاً.

وهكذا ينبئ الكاتب عن هدفه وهو الكشف عن قانون للنص، انطلاقاً من أن الحجة في الإسلام ليست لشيء سوى للنص الخالص كتاباً أو سنة، في البدء كان النص حسب تعبيره، وأن "الإلزامية" في النص الخالص أيضاً ليست لشيء سوى للنص الجازم وجوباً أو حرمةً، وأن عدم النص هو في ذاته "نص" بالإحالة 
على دائرة المباح، مما يؤدي ضرورة على القول بأن الأحكام في الإسلام لا تخرج عن دائرتين اثنتين، دائرة المباح أولاً ودائرة الالزام ثانياً، وبقدر ما تضيق الأولى تتسع الثانية، وبقدر ما تتسع الأولى تضيق الثانية. وهكذا فإن ما سكت النص عنه كان مقصوداً، ومِن تََّّ فإن القول بالإجماع أو القياس وما ألحق بكما من مرجعياتٍ مفارقة للنص، مناقضةٌ لمقصود الشارع العليم في إنشاء دائرة الحرية، أو الكشف عن هذه الدائرة التي هي كائنةٌ بالأساس على سبيل الأصالة والابتداء، وذلك أن الإجماع والقياس كما هو معروف ووفقاً لصريح الشافعي نفسه لا يبدأن في "العمل" إلا عند سكوت النص، في حين لأن الغرض من سكوت النص، إنما خو على وجه التحديد "وقف العمل" أي وفق الإلزامية بشقيها في الإيجاب والتحريم.

لقد كان "العقل الإسلامي" في معظمه ولا يزال يتعامل مع السكوت كظاهرة استاتيكية معبرة عن الثبات من قبل النص ويتجاهل دلالاته الحقيقية بوصفه إحالةً مض نصية إلى دائرة المباح أي إلى الزمن المحرك بكل معطياته وملابساته، ويبدو ذلك واضحاً مع الشافعي الذي راح يضيق دائرة المباح من حيث أراد الشارع أن يوسعها، كما بتحلى في صيغة القياس عنده حين عمل على إحالٍٍ للمسكوت عنه على النصوص، وكأنه بذلك رد على النصوص إحالتها، وانتئت على دائرة الحرية الانسانية أو على حسب تعبير المؤلف دائرة "المسكوت عنه" أو دائرة البراءة الأصلية بتعبير بعض الأصوليين. ربما شكّل ذلك جواباً حقيقياً لسؤال طرحه عدد كبير من الكتاب، ربما كان أولم زكي نجيب محمود في كتابه "تجديد الفكر العربي" حين تساءل عن غياب مسألة الحرية داخل التراث العربي الإسلامي، ليأتي الجواب مع عبد الجواد ياسين الذي يرى أم غياب مسألة الحرية كمقابل ضروري لفكرة النظام في نظرية السلطة يعود إلى أن المنظومة الفقهية السلفية في بجموعها قد تحورت حول "النظام" في نظرية السلطة يعود إلى أن المنظومة الفقهية السلفية في بجموعها قد تححورت حول "النظام" فبالغت في الحديث عن "الفننة" و "وجوب الطاعة" بقدر ما أغفلت وتغافلت عن تقنين الحرية الفردية في مواجهة السلطة بوصفها الوجه الآخر من العملة في قضية السلطة.

وكما شكَّل القياس اجتراحاً لدائرة المباح، فإن الإجماع كما جعله الشافعي -أيضاً - مصدراً "للتشريع" حين قننه نظرياً كمرجعية مستقلة وملزمة، مستقلةً عن النص، وملزمةٍ للأمة المسلمة على الدوام، شكل هذا -أي الإجماع- اجتراحاً آخر مهماً لدائرة البراءة الأصلية، بل امتد أثره كأصلٍ يمارس سلطته السلفية حتى 
الوقت الحاضر، فالحكم المبني على إجماع الصحابة يلزم التابعين ومن بعدهم من المسلمين، جيلاً بعد جيل إلى غاية الزمان، وكذلك إجماع التابعين يلزم الأمة إلى الأبد، ثم إجماع من بعدهم وهكذا إلى ناية الدهر. وربما تكون عبارة الشافعي (لا يجوز لمن استأهل أن يكون حاكماً أو مفتياً أن يجكم، ولا يفتي إلا من جهة خبرٍ لازم) والخبر اللازم في مفهوم الشافعي هو نفسه الماضي أي (الإجماع والآثار وما وصفت من القياس) على حد تعبيره.

فصيغة (إلا من جهة علم مضى قبله) بالغة الدلالة على تقريره بتنحية "الحاضر" في كل حين أن يحكم نفسه، حتى إذا ما أصبح هذا الحاضر "ماضياً" كان له أن يحكم العصر اللاحق عليه، وهكذا نجد أنفسنا حيال "معيار زمانٍ مضض" يلخص كأبلغ ما يكون التلخيص جوهر "السلفية" كتيارٍ في الفقه وطريقة في التفكير، إن الماضي هنا لا يقصد به محض النص ولا إجماع الصحابة فحسب، بل كذلك "الآثار" أي أقاويل الصحابة ثم التابعين.

لقد برع المؤلف في تلمس جوهر الأزمة المستحكمة داخل الجوهر العربي الإسلامي، غير أنه لم يبين لنا الأسباب التي أهَّبت لسيادة هذا التيار السلفي على حساب تيارات أخرى يعدّها "لا سلفية" ويخصص لها مكاناً لا بأس به من كتابه، بل كل ما نخصل عليه لأجل ذلك قوله : (كان لظروف النشأة التاريخية التي تبلورت فيها مدرسة الحديث (وهي مدرسة السلف بلا شك حسب رأيه) دور في أن تكون هي المدرسة التي (قدّرت) لها السيادة على العقل المسلم، وهي التي كتبت بيدها منظومة الفقه الإسلامي المعتمدة حتى اليوم على أها الإسلام، وقد لعبت هذه الظروف أيضاً في لجم الخصومة مع أهل الرأي والاجتهاد، مما كرس النفور

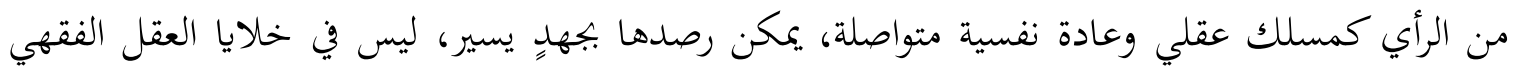
الإسلامي الراهن فحسب، بل على مستوى سلوكه الفكري والاجتماعي والسياسي العام) وهكذا فإن كلمة (قدّرت) تخفي في طياتما أسباباً كان من الجدير البحث فيها والكشف عنها، ولو كان يتعذر للكاتب أها لا تدخل ضمن اهتمامه الرئيس. وبعد أن حاول تشخيص الأزمة وبيان التباساها وإشكالياها فإنه انتقل ليرى انعكاس ذلك على المستوى السياسي للأمة وعلى رأسها السلطة - همُّ الكتاب - مستحضراً نص فاقع الدلالة لأحمد بن حنبل (من غَلَبَهم بالسيف حتى صار خليفة ومّمّي أمير المؤمنين لا يحلُّ لأحد يؤمن بالله 
واليوم الآخر أن يبيتَ ولا يراه إماماً عليه، براً كان أو فاجراً، فهو أمير المؤمنين) فعبارة (لا يحلٌّ) في هذا النص تضعنا - كوالكلام هنا للمؤلف - في بساطةٍ مذهلةٍ، حيال حكمٍ شرعي بالتحريم، ليس على من يعلن الخروج والعصيان فحسب، وإنما على من ينفي في تصوره الداخلي صفة الشريعة عن الحكومة الفاسدة الجائرة، وليس ذلك فحسب، بل إن الإثم يلحق بمن لا يثبت لهذه الحكومة صفة الشرعية، أو بعبارة ابن حنبل (بمن يبيت ولا يراه إماماً عليه) وهو ما يعني في عبارةٍ مكافئة، وجوب اتخاذ موقف إيجابي باعتقاد الشريعة، لا بجرد موقف سلبي بالامتناع عن الاعتقاد.

إن مكمن الحنطر هنا، أن ابن حنبل لا يؤرخ حدتاً أو يقدم رأياً، كما أنه لا يفتي بصدد واقعة غخصوصة يمكن الحديث فيها عن الضرورة والإكراه، وإنما هو ينظر نظريةً ويؤصل حكماً ويشرع تشريعاً له صفة التأييد والدوام.

فهل يسهل علينا أن نرى إلى أي مدى بلغت هيمنة "الواقع"؟ وإلى أي مدى كانت النظرية انعكاساً للتاريخ أي لجبروت الواقع السياسي المفروض بالقوة؟ وإلى أي مدى كان النص يتأخر حين يِراد له أن يتأخر؟ ويبدو أن هذه النقطة الرئيسية التي حاول المؤلف إبرازها في فصول كتابه اللاحقة التي تقوم على أن المبادئ النظرية للسلطة ليست أصيلة في نسيج النص الخالص، مما يؤكد الدور التشكيلي الطاغي للتاريخ، تاريخ السلطة السياسية ولا سيّما في صياغة الإسلام كما هو بين أيدي الناس اليوم، ونتيجة لذلك يخلص إلى أن النظرية السلفية في الإمامة، أو نظرية الخلافة لدى أهل السنة والجماعة ليست نتاجاً مباشراً لنص إلزامي خالص، وإنما هي من صناعة التاريخ أو هي بعبارة أخرى من صناعة السلطة.

ووصولاً إلى ذلك فقد لجأ إلى توظيف مصطلحين برع في نحتهما واستخدامهما معاً، الأول هو "الاستنصاص" ويعني طلب النص بعد الحاجة إليه على مستوى التمذهب، والثاني هو "التنصيص" ويعني تصنيع النص بطريقة تركيبية موافقة للأحداث، سداً لحاجة المذهب، وهو ما يعني أن التمذهب سابق على النص وليس العكس. وهذا ما وظفه في قراءة التراث الشيعي الذي انتهى إلى أنه محض "فكر" ومخض "سياسة" أُلبس أردية عقيدية، لم تكن في معظمها موصولة بالنصوص، بل تم خلق النّصوص لها عن طريق 
لكنه انتصر بل حارب من أجل المعتزلة الذين أسسوا منهجاً نقدياً شاملاً كانت خسارتنا في صياغة عميقة وواسعة، إذ نتج عن ذلك أن "النسخة" المعتمدة للسنة كنص فائي ليست كذلك في الحقيقة، فهي لا تمثل من حيث الكم حقيقة النص الصحيح للسنة، وقد كان من شأن المنهج النقدي الشامل لو تم إعماله أن يجنب النص السني الصحيح مجاورة الكثير من الأوهام والخرافات التي ألبست ثوب الأحاديث ثم أضيفت إليه بغير حق.

إن مشروع المؤلف في تطبيقه لمنهجه النقدي يهدف إلى عرض الإسلام إلى العالم كما هو في حقيقته وليس كما هو في المنظومة التاريخية، وهذا لم يتم بغير دعامتين: الأولى: أن تنحى كل المصادر اللانصية التي اعتمدتا المنظومة السلفية، وهو ما يعني إعادة قراءة ثم

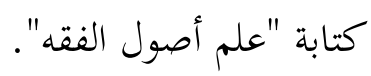
والأخرى: أن تحذف كل الإضافات التي حملت على نص السنة، من جراء المنهج الإسنادي في جمع الروايات والأخبار، وهو ما يعني إعادة قراءة ثم كتابة "علم الحديث". لن يتم ذلك بغير "الحاسة النقدية" التي هي بنت العقل والحرية أي بنت الإسلام الحقيقي الأصيل، أي الإسلام الذي نقرأه في النص الخالص.

وينتصر المؤلف بعد ذلك بشكل طبيعي لمدرسة ابن حزم الذي عمل على توسع دائرة الحرية الإنسانية بإلغائه دعوى القياس والإجماع التي تمثل سلطة الفقه والسلطة السياسية اللتين ساهمتا بوعي أو بغير وعي في تنويم العقل المسلم وحرمانه من فرصة التدريب على ممارسة الحرية. وإذا كان الفصل الثاني قد خصص لدراسة التأويل السياسي للنص القرآني والفصل الثالث لدراسة النص النبوي للكشف عن سلطة النص ونص السلطة، فإْما يشكلان معاً القسم التطبيقي والتقني للمنهج الذي عرضه المؤلف في فصل كتابه الأول، مستحضراً نصوصاً غاية في الغرابة والدلالة، الدلالة من حيث بياها الصريح على ظروف نشأة النص السياسي، والغرابة لشهرة النص وتداوله دون أن يبلغ عند أحدٍ مستوى التفكير فيه، وليخرج بنتائج مهمة من خلال دراسته وتحليله للنصوص، كالشروط الواجب توفيها في الحاكم أو رئيس الدولة، إذ يقرر أن هذه 
الشروط سكت القرآن عن الخوض فيها على وجه التفصيل، ولكن ينبغي ألا تتعارض في شيء منها مع التصور الإجمالي العام الذي ترسمه المبادئ الكلية للقرآن، وعلى رأسها مبدأ المساواة والعدل بين الناس، سواءً على مستوى الأفراد أو القبائل أو الشعوب. وبذلك لا تعدو النصوص التي تنص على شرط قرشية الخليفة سوى أحداث تاريخية أراد الفقه لها أن تقع على نهٍِ ما، فأعاد صياغتها على النحو الذي أراد، ولما كان العصر عصر تدوين للنصوص، فقد كان من السهل أن يتداخل الفقه مع النص تداخلاً يصعب فك الاشتباه معه وتلك حقيقة في غاية الأهمية والخطورة.

فالإسلام "أنشئ شرعية دستورية" مستقلة عن الواقع، وليست مخاصمة له أو نافية، وإنما سابقة عليه وبجردة منه، وهي بحكم مصدريتها النصية قابلة للتكرار باستمرار، بل مدعو إلى إنشائها على الدوام، وليس في الأمر معجزة ولا خارقة، بل هو حكم النصوص العامة في القرآن التي قتف بالعدالة والحرية والشورى والمساواة بين البشر، والتي ليس من بينها على الإطلاق أن يكون الحكم مقصوراً على قريش. بيد أن النقطة الأهم التي يثيرها الكاتب بجرأة وشجاعة هي نفي المقولة القائلة بأن كل ما ورد في صحيحي البخاري ومسلم نصوص مقطوع بصحتها، بل يجعل ذلك فرضية شائعة تركزت في العقل السلفي، ويدلل على ذلك بالأمثلة بائنة الدلالة، ثم يورد التأويلات المتعسفة التي راحت تبرر الحديث وتأويله مما يوقعها في مآزق محرجة تدل على مدى العنت ومبلغ التكلف الذي يواجهه الشارح بحثاً عن مخرجٍ لحديث مشكل لا حل له.

من تلك الأمثلة ما ورد في أحاديث الفتنة والملاحم، فهو يعمد إلى قراءة مرويات البخاري ومسلم في ذلك على ضوء التاريخ قراءة سياسية ليبين بعد ذلك أن معظمها نصوص سياسية تتكلم عن التاريخ، وليست متوناً فقهية تشرع للمستقبل. ولا بأس أن نذكر هنا أحد الأمثلة البالغة الدلالة، ففي الحديث الأول من أحاديث الباب يورد

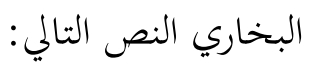


(إنكم سترون أثثر وأموراً تنكروها قالوا فما تأمرنا يا رسول الله؟ قال أدّوا إليهم حقهم وسلوا الله حقكم) والمعنى كما هو واضح أن حق الحكام معجّلٌه في الدنيا، وحق المحكومين مؤجلٌٌ في الآخرة، وهو المعنى الذي سيتكرر بإلحاح في أربعة من الأحاديث الخمسة الباقية في الباب، ويأتي دور الشراح ليكرسوا في العقل المسلم مفهوم الاغزام والقهر المتواصلين حيال السلطة، فيجعلوا من حق الحكام الذين ينبغي أن يؤدى إليهم (بذل المال الواجب في الزكاة، والنفس في الخروج إلى الجهاد عند التعيين ونخو ذلك) على حين يفسرون قوله (وسلوا الله حقكم) بأن (يلهمهم إنصافكم ويبدلكم خيراً منهم).

وهكذا ينحصر دور المحكومين في الدعاء إما بأن يلهم الله الحكام أن ينصفوهم، وإما بأن يبدهم الله تعالى بقوته وجبروته، فهل يمكن لهذا المعنى أن يكون أصيلاً في الدين الإسلامي؟ هل يمكن لهذا السلبية ذات الطابع الخانع أن تكون نداء الإسلام إلى العالم؟ هل يمكن لتلك الروح الانسحابية أن توافق مضمون الكتاب وهو يهيب بالأمة أن تدعو إلى الخير؟ أو وهو يدعوها إلى مجافاة الاستبداد لكون الأمر شورى بينهم؟ وهل يمكن للاستبداد أن يجد مناخاً أنسب من ذلك حتى يشتد ويقوى؟ ربما تحمل مضامين الأسئلة نفسها الأجوبة من داخلها.

إن المؤلف يختم أخيراً بأن السنة ليست مرادفة لأخبار الآحاد جميعاً، وحين ننفي عن السنة هذه المرويات التي تخالف الكتاب وتناقض العقل وتعارض الثابت من شواهد التاريخ نكون قد دافعنا عن السنة، وحينغٍِ، سوف يمكن للإسلام أن يقدم للعالم وللعقل الإنساني المعاصر طرحه الإيماني العظيم الذي يصعب على البشرية رفضه، لأنه سيكون وحياً خالصاً قطعي الإسناد إلى الله تعالى أي صالحاً للزمان كله والمكان كله، ولن يكون طرحاً تاريخياً مبصوماً ببصمة القرون، ولا طرحاً جغرافياً مصبوعاً بصبغة الشعب والإقليم. لا أجدني مبالغاً إن قلت إن هذا الكتاب سيحدث ثورة في العقل السلفي مبدداً الكثير من قطعياته ناسفاً معظم مسلماته، ويكفي أن أقول إنه لن يجزئه مقالٌ عنه، ولن يكفيه كتاب يخصص له، ولكن ما لا يدرك كله لا يترك جلُّه، وحسبي أن أكون قد أثرت أهم نقاط الكتاب وإشكالياته علها تحفز العقول للتفكير أو إعادة التفكير بما هي قائمة عليه، وتستفز الأقلام للكتابة لتوسع دائرة البحث والنقاش بما يشكل دائرة أوسع للتواصل والتلاقح الفكري الذي يمثل البذرة الأولية لأية هضة حضارية ثقافية. 